\title{
Psoriasis ve Malignite Birlikteliği: 5 Yıllık Verilerin Retrospektif Analizi
}

\section{Coexistence of Psoriasis and Malignancy: Retrospective Analysis of 5- Year Data}

\author{
Fatmagül Gülbaşaran ${ }^{1 *}$, Kamer Gündüz ${ }^{2}$ \\ ${ }^{1}$ Salihli Devlet Hastanesi Dermatoloji Kliniği, Manisa, Türkiye. \\ ${ }^{2}$ Manisa Celal Bayar Üniversitesi Tıp Fakültesi Deri ve Zührevi Hastalıklar Anabilim Dalı, Manisa, Türkiye. \\ e-mail: fatmagulkls@gmail.com, kamergunduz@gmail.com. \\ ORCID: 0000-0002-7550-6052 \\ ORCID: 0000-0002-1319-9237 \\ *Sorumlu yazar/ Corresponding Author: Fatmagül Gülbaşaran
}

Gönderim Tarihi / Received: 05.12.2020

Kabul Tarihi / Accepted: 16.09.2021

DOI: $10.34087 /$ cbusbed. 836350

\section{$\ddot{\mathbf{O z}}$}

Giriş ve Amaç: Kronik inflamatuar bir hastalık olan psoriasisde, immünolojik değişiklikler ve uzun süreli kullanılan sistemik immünsüpresif tedaviler nedeniyle kanser riskinin arttığı düşünülmektedir. Bu konuda yapılan çalışmalarda çelişkili sonuçlar elde edilmiş, psoriasis ile malignite riski arasındaki ilişki henüz tam olarak aydınlatılamamıştır. Bu çalışmada psoriasisli hastalarda malignite riskinin araştırılması amaçlanmıștır.

Gereç ve Yöntemler: Manisa Celal Bayar Üniversite Hastanesi elektronik hasta kayıt sisteminden retrospektif tarama yapılarak, 2013 ile 2018 yılları arasında psoriasis tanısı olan 1669 hasta çalışmaya dahil edilmiştir. Aynı dönemde Dermatoloji polikliniğine başvuran ve psoriasis tanısı olmayan 3870 hasta kontrol grubu olarak değerlendirilmiștir. Her iki grupta, dermatolojik tanı aldıkları tarihten 1 ay sonrasından başlayarak kanserin tipi ve kanser tanısı aldıkları zaman kaydedilmiştir.

Bulgular: Psoriasis ve kontrol gruplarının yaş ortalamaları sırasıyla 40,33 $\pm 17,58$ ve 40,22 $\pm 16,91$ olarak bulunmuştur. Psoriasis grubunun \%47,5'i (n=793), kontrol grubunun \%48,9’u (n=1892) kadınlardan oluşmaktaydı. Kanser bulunma sıklığ 1 psoriasis grubunda \%3,62, kontrol grubunda \%4,25 olup, istatistiksel olarak anlamlı farklılık saptanmamıştır. Psoriasisli hasta ve kontrol grubu arasında, kanser tanı yaşı, kanserli hastaların cinsiyet dağılımı açısından anlamlı farklılık bulunmamıştır. Herhangi bir immünsupresif ilaç öyküsü bulunmasının genel olarak, ya da ilaçlardan herhangi birinin psoriasis hastalarında kanser riski üzerine anlamlı etkisi saptanmamıştır.

Sonuç: Sonuç olarak, beş yıllık takipte psoriasise ya da psoriasis tedavisinde kullanılan ilaçlara bağlı olarak artmış bir malignite riski saptanmamıştır. Retrospektif bir çalışma olduğu için kanser riskini artırabilecek her parametrenin tam kontrolünün sağlanamaması bu çalışmanın kısıtlılı̆̆ıdır. Kısa süreli tedavi alan hastaların da birlikte analiz edilmesi, uzun süre tedavi alan hastalarda kanser riskini istatistiksel olarak maskelemiş olabilir. Bu nedenle uzun yıllar sürecek şekilde planlanmış, prospektif randomize kontrollü çalışmaların gerçekleştirilmesine ihtiyaç vardır.

Anahtar kelimeler: İmmunsupresif tedaviler, Kanser, Malignite, Psoriasis.

\footnotetext{
Abstract

Objective: Psoriasis is a chronic inflammatory disease and it is suggested that there may be an increased risk of malignancy because of immunological alterations and long-term immunosuppressive therapies. There are conflicting results and the association between psoriasis and malignancy is still unclear. The aim of this study was to investigate the risk of malignancy in patients with psoriasis.

Materials and Methods: In this retrospetive study, 1669 patients diagnosed with psoriasis between January 2013 and January 2018 in the electronic patient registration system of Manisa Celal Bayar University Hospital were enrolled in the study. The control group consisted of 3870 non-psoriatic patients randomly determined among patients who admitted to the dermatology clinic within the same time period. In both groups, cancer type and the age of the cancer diagnosis were recorded for those who had cancer diagnosis at least 1 month after the dermatologic diagnosis.
} 
Results: The mean age of the psoriatic group was $40.33( \pm 17.58)$ and the control group was $40.22( \pm 16.91)$; women in the psoriatic group were $47.5 \%(n=793)$ and $48.9 \%(n=1892)$ in the control group. Cancers were present in $3.62 \%$ of the psoriatic group and $4.25 \%$ of the control group without statistical significance. There was no significant difference between the two groups in terms of cancer age or gender distribution of cancer patients. No significant effect of immunosuppressive drugs on cancer risk in psoriasis patients were detected in general or with related to any of the drugs.

Conclusion: In conclusion, no increased risk of malignancy due to psoriasis or the drugs used in the treatment of psoriasis was found in the five-year follow-up. As a retrospective study, lack of full control of every parameter that may increase cancer risk is the limitation of this study. Analyzing the patients on short-term therapy together may have statistically masked the cancer risk in patients receiving long-term therapy. Therefore, prospective randomized controlled trials that will last for many years are needed.

Keywords: Cancer, Immunosuppressive treatments, Malignancy, Psoriasis

\begin{abstract}
1. Giriş
Derinin kronik inflamatuar bir hastalığı olan, çevresel ve genetik faktörler ile tetiklenen psoriasis, dünya nüfusunun yaklaşık \% 2 ile \% 3'ünü etkilemektedir [1,2]. Psoriasisin sadece deri ve eklemleri etkileyen bir hastalık olmadığ kronik subklinik sistemik inflamasyon nedeniyle diyabet, obezite gibi çeşitli sistemik komorbiditelerle de ilişkili olduğu bilinmektedir [3].
\end{abstract}

Pek çok kanser türünde, immün sistem aracılı inflamatuar değişiklikler ile ilişki gösterilmiştir [4-6]. Psoriasisde meydana gelen immün aracilı kronik inflamatuar değişiklikler ile birlikte, hastaların uzun süreli kullandıkları sistemik immünsüpresif ilaçlar dikkate alındığında, psoriasisde kansere karşı olan immün denetimin zayıflayabileceği ve kanser oluşumunun kolaylaşabileceği düşünülmüştür. Ancak psoriasis ile artmış malignite riski arasındaki ilişki hala tam olarak aydınlatılamamıştır, bu konuda farklı merkezlerden bildirilerin sonuçları değişkenlik göstermektedir [2,7]. Bu çalışmanın amacı, psoriasisli hastalarda malignite riskinin araştırılmasıdır.

\section{Materyal ve Metot}

\subsection{Etik Onay}

Çalışma protokolu Manisa Celal Bayar Üniversitesi Yerel Etik Kurul Komitesi tarafından onaylanmıştır.

2.2. Çalışma tipi, veri kaynağl ve çalışma popülasyonu $\mathrm{Bu}$ çalışma retrospektif hastane-temelli bir vakakontrol çalışmasıdır. Manisa Celal Bayar Üniversite Hastanesi elektronik hasta kayıt sisteminden retrospektif tarama yapılmış ve 5 yıllık sürede (20132018) Dermatoloji başvuruları içerisinde psoriasis tanıs1 olan tüm hastalar (ayaktan ve yatan toplam 1669 hasta) çalışmaya dahil edilmiştir. Kontrol grubunu, aynı zaman aralığı içerisinde Dermatoloji kliniğine psoriasis ve melanom (MM)/non-melanom (NM) deri kanserlerinden farklı tanılarla başvuran hastalar arasından randomize seçilen yaş ve cinsiyet uyumlu 3870 kişi oluşturmuştur. Dermatolojik tanı almadan önce mevcut kanser tanısı olan hastaların kanser tanıları dahil edilmemiştir. Aranan tanı kodları iki defadan az girilmiş olan hastalar, tanıları kesinleşmeme ihtimali nedeniyle çalışmadan dışlanmıştır. Her iki grupta da, dermatolojik tanıdan (psoriasis tanısı ve kontrol grubu için diğer dermatolojik tanılar) en az 1 ay sonra verilmiş olmak şartıyla, hastanede herhangi bir klinikte kanser tanısı almış olanların hasta bilgileri detaylıca taranarak kanser tipleri, kanser tanı yaşları ve verilen tedaviler dikkate alınarak kanser tanı kodları teyit edilmiş, kanser tipleri ve tanı yaşları kaydedilmiştir. Psoriasis hastalarının immünsupresif tedavileri, en az üç takipli reçete koşulu ile kaydedilmiştir.

\subsection{Istatiksel Analiz}

İstatistiksel analizler SPSS 24.0 kullanılarak yapılmış ve $\mathrm{P} \leq 0.05$ anlamlı kabul edilmiştir. Sürekli değişkenler, ortalama \pm standart $\quad$ sapma ve medyan, minumum-maksimum değerlerle tanımlanmıştır. Kategorik değişkenler yüzdeler ile karşılaştırılmış, normal dağılımın belirlenmesi için Kolmogorov Smirnov testi kullanılmıştır. Sürekli değişkenler için bağımsız grup karşılaştırmalarında Mann-Whitney U testi kullanılmıştır. İki grup arasındaki kategorik değişkenler için ki-kare (Pearson ve Fisher's Exact), risk faktörlerinin belirlenmesinde lojistik regresyon analizi kullanılmıştır.

\section{Bulgular ve Tartıșma \\ 3.1.Bulgular}

Psoriasis ve kontrol hastalarının, yaşları 1 ile 84 arasında değişmekte olup, yaş ortalaması psoriasis grubunda 40,33 ( $\pm 17,58)$, kontrol grubunda 40,22 ( \pm $16,91)$ olarak saptanmıştır. Psoriasis grubunda kadınlar $\% 47,5(\mathrm{n}=793)$ ve kontrol grubunda \%48,9 $(\mathrm{n}=1892)$ olup, yaş ve cinsiyet açısından iki grup arasında anlamlı fark saptanmamıştır (

Psoriasis grubunda toplam kanserlerin bulunma siklığ \%3,62 ve kontrollerde \%4,25 olup, karşılaştırıldığında anlamlı farklılık saptanmamıştır $(\mathrm{p}=0,27)$.

Tek tek kanser tiplerinin bulunma yüzdeleri karşılaştırıldığında, dijital hasta kayıt sistemindeki tanı kodu verilerine göre, sadece kutanöz $T$ hücreli lenfomalar (KTHL) psoriasis grubunda anlamlı derecede daha fazla bulunmuştur (\%0,66'ya karşın, $\% 0,28) \quad(\mathrm{p}=0,04)$. Bununla birlikte, yöntemde de belirtildiği gibi; kanser tanı kodu çıkan tüm hastaların, kanser tanı kodlarının teyidi için, sonrasında dosyaları detaylıca taranmış ve bazı psoriasis lezyonlarının bir döneminde, bir KTHL olan mikozis fungoides (MF) düşünülerek MF tanı kodu girildiği, ancak takipte ardışık biyopsi sonuçlarında bunların sadece MF'i taklit eden psoriasis lezyonları olduğunun tespit edildiği saptanmıştır. MF ve psoriasisin ayırıcı tanıda yer alan hastalıklar olmasından kaynaklanan bu durumun hatalı etkisini kaldırmak için, psoriatik grupta 
mikozis fungoides tanısı girilen bu 5 hasta çıkartıldıktan sonra yapılan analizde; kutanöz T hücreli lenfomalar açısından da psoriatik ve non-psoritatik grupta anlamlı farkın ortadan kalktığı gözlenmiştir (surasiyla \% 0,36 ve \% 0,28, p=0,62). (Tablo 1 ).

Tablo 1. Psoriasis ve Kontrol Grubunda Kanser S1klıkları

\begin{tabular}{|c|c|c|c|}
\hline & $\begin{array}{c}\text { Psoriasis } \\
(\mathrm{n}=1669) \\
\%\end{array}$ & $\begin{array}{c}\text { Kontrol } \\
(\mathrm{n}=3870) \\
\%\end{array}$ & $\mathbf{P} *$ \\
\hline $\begin{array}{l}\text { Tüm Kanserler } \\
\text { (MM ve NM deri kanserleri hariç) }\end{array}$ & 3,62 & 4,25 & 0,27 \\
\hline $\begin{array}{l}\text { Tüm kanserler deri kanserleri hariç } \\
\text { Yanlış Tanı MF’ ler Çıkarılmış }\end{array}$ & 3,32 & 4,25 & 0,12 \\
\hline Kutanöz T Hücreli Lenfoma & 0,66 & 0,28 & $0,04 *$ \\
\hline $\begin{array}{l}\text { Kutanöz T hücreli Lenfoma, } \\
\text { Yanlış Tanı MF’ ler Çıkarılmış }\end{array}$ & 0,36 & 0,28 & 0,62 \\
\hline Bronş-Akciğer & 0,48 & 0,26 & 0,19 \\
\hline Ürolojik & 0,48 & 0,65 & 0,47 \\
\hline Hematolojik & 0,42 & 0,85 & 0,08 \\
\hline Endokrin & 0,42 & 0,49 & 0,73 \\
\hline Meme & 0,36 & 0,49 & 0,5 \\
\hline Jinekolojik & 0,24 & 0,16 & 0,5 \\
\hline $\begin{array}{l}\text { Gastrointestinal Kanal } \\
\text { (Mide, İnce ve Kalın Bağısak, Rektum) }\end{array}$ & 0,18 & 0,26 & 0,58 \\
\hline Farinks-Larinks & 0,18 & 0,21 & 0,84 \\
\hline Beyin & 0,12 & 0,08 & 0,63 \\
\hline Karaciğer & 0,06 & 0,05 & 0,9 \\
\hline Yumuşak Doku, Bağ Doku, Vasküler & 0 & 0,10 & 0,19 \\
\hline Diğer & 0 & 0,31 & - \\
\hline
\end{tabular}

*Ki-kare testi.

Kanserin ortalama başlangıç yaşı psoriasis grubunda $54,6 \pm 14,3$, kontrol grubunda 55,94 $\pm 16,2,(\mathrm{p}=0,204)$ ve kadın cinsiyet oranları; psoriatik kanserli grupta $\% 54,5$ ve kontrol grubunda kanserli hastalarda \%60,5 $(\mathrm{p}=0,375)$ olup, iki grup arasında, kanser görülme yaşı açısından ya

da cinsiyetle kanser varlığ görülmemiştir. Herhangi bir immünsupresif ilaç öyküsü bulunmasinın genel olarak, ya da tek tek kullanılan ilaçların psoriasis hastalarında kanser riski üzerine anlamlı etkileri saptanmamıştır (Tablo 2).

Tablo 2. Sistemik İmmünsupresif Tedavilerin Psoriasis Hastalarında Kanser Riskine Etkisi

\begin{tabular}{|c|c|c|c|}
\hline & \multicolumn{2}{|c|}{ Psoriasisli Hasta Grubu } & \multirow{3}{*}{$\mathrm{P}^{*}$} \\
\hline & Kanser Yok $(n=1609)$ & Kanser Var $(n=60)$ & \\
\hline & $\mathrm{n}(\%)$ & $\mathrm{n}(\%)$ & \\
\hline Metotreksat kullananlar $(\mathrm{n}=\mathbf{3 9 3})$ & $385(\% 98,0)$ & $8(\% 2,0)$ & 0,06 \\
\hline Siklosporin kullananlar $(\mathrm{n}=\mathbf{5 0})$ & $47(\% 94)$ & $3(\% 6)$ & 0,42 \\
\hline Biyolojik ajan kullananlar $(n=189)$ & $182(\% 96,3)$ & $7(\% 3,7)$ & 0,93 \\
\hline $\begin{array}{l}\text { Herhangi bir sistemik ilaç öyküsü } \\
\text { bulunanlar }(n=506)\end{array}$ & $494(\% 97,6)$ & $12(\% 2,4)$ & 0,08 \\
\hline
\end{tabular}


Psoriasisde kanser riskinin belirli yaş gruplarına spesifik olup olmadığını anlamak için, hastalar yaşa göre gruplandırıldığında herhangi bir yaş grubu ile psoriasis için artmış kanser riski saptanmamıştır. (Tablo 3)

Tablo 3. Yaş Gruplarında Kanser Sıklıkları

\begin{tabular}{|c|c|c|c|c|c|}
\hline & & $\begin{array}{c}\text { Psoriasis } \\
\mathrm{n}(\%)\end{array}$ & $\begin{array}{c}\text { Kontrol } \\
\text { n (\%) }\end{array}$ & $\begin{array}{l}\text { Total } \\
\mathrm{n}(\%)\end{array}$ & $\mathrm{P}$ \\
\hline \multirow[t]{2}{*}{ 0-19 yaş } & Kanser + & $0(\% 0,0)$ & $5(\% 1,5)$ & $5(\% 0,9)$ & \multirow[t]{2}{*}{0,16} \\
\hline & Total $n$ & 216 & 331 & 547 & \\
\hline \multirow[t]{2}{*}{ 20-39 yaş } & Kanser+ & $8(\% 1,3)$ & $28(\% 1,6)$ & $36(\% 1,5)$ & \multirow[t]{2}{*}{0,64} \\
\hline & Total n & 595 & 1733 & 2328 & \\
\hline \multirow[t]{2}{*}{ 40-69 yaş } & Kanser + & $26(\% 4,3)$ & $66(\% 5,8)$ & $92(\% 5,3)$ & \multirow[t]{2}{*}{0,19} \\
\hline & Total $\mathrm{n}$ & 599 & 1132 & 1731 & \\
\hline \multirow[t]{2}{*}{ 70-89 yaş } & Kanser + & $19(\% 8,0)$ & $57(\% 11,2)$ & $76(\% 10,2)$ & \multirow[t]{2}{*}{0,19} \\
\hline & Total $\mathrm{n}$ & 237 & 511 & 748 & \\
\hline \multirow[t]{2}{*}{90 yaş üstü } & Kanser + & $2(14,3)$ & $3(\% 8,8)$ & $5(\% 10,4)$ & \multirow[t]{2}{*}{0,62} \\
\hline & Total $\mathrm{n}$ & 14 & 34 & 48 & \\
\hline
\end{tabular}

Yaş ve cinsiyetin, kanser sıklığı üzerine olası etkilerini kontrol etmek için yapılan çok değişkenli lojistik regresyon analizinde, psoriasis için rölatif kanser riski anlamlı bulunmamıştır. (Tablo 4)

Tablo 4. Psoriasisde Yaş ve Cinsiyet ilişkili Rölatif Kanser Riski

\begin{tabular}{|c|c|c|c|c|}
\hline \multirow{2}{*}{} & $\mathrm{p}$ & O.R. & \multicolumn{2}{|c|}{$95 \%$ C.I. } \\
\cline { 4 - 5 } & & & Alt Sinır & Üst Sinır \\
\hline Psoriasis & 0,06 & 0,73 & 0,53 & 1,00 \\
\hline Yaş & $0,00 *$ & 1,05 & 1,04 & 1,06 \\
\hline Cinsiyet & 0,68 & 1,06 & 0,80 & 1,42 \\
\hline
\end{tabular}

Çok değişkenli lojistik regresyon analizi

\subsection{Tartışma}

Psoriasis ve malignite ilişkisini araştıran çalışmalarda çelişkili sonuçlar mevcuttur [2,7-9]. En çok kutanöz T hücreli lenfomalar olmak üzere lenfomalar psoriasis ile ilişkilendirilmektedir [9]. Çalışmalar genellikle hastane elektronik kayıt sistemleri, sağlık sigorta kayıt taramaları ya da ulusal resmi sağlık verileri üzerinden yapılan elektronik tarama sonuçlarına dayanmakta [10], kutanöz lenfoma ve psoriasis ayırıcı tanı hatasının birebir hasta bilgileri ve takibi yapılarak düzeltilmesinin sağlanamaması bu konuda kısıtlılık oluşturmaktadır. Psoriasiste kanser riski üzerine epidemiyolojik çalışmaların geniş bir meta-analizi de [11] psoriasis ile kutanöz lenfomalar arasında bildirilmekte olan güçlü ilişkiyi tanısal karışıklık nedenine bağlamıștır. Bizim çalışmamızda da elektronik hasta kayıt sistemi tanı kodu taraması ile, kutanöz lenfomalar açısından anlamlı farklılık ortaya çıkmış, fakat bu hastaların dosyalarının, patoloji raporlarının, tedavi takiplerinin detaylı incelenmesi sonucunda bu vakaların psoriasis vakaları olduğu anlaşılmıștır. Buna göre düzeltilerek yapılan analizde, kutanöz lenfomalar için de, psoriasis ve kontrol grubu arasında anlamlı farklılık ortadan kalkmıştır.

Çalışmamızda MM ve NM deri kanserleri hariç tutulduğunda, psoriatik grupta genel olarak kanser varlığg, herhangi bir özel kanser türünün görülme sıklığı, kanser görülme yaşı ve cinsiyet oranları kontrol grubundan farklı bulunmamıştır. Çalışmamızın sonuçları psoriasis hastalığ 1 için artmış bir malignite riski göstermemektedir. Pek çok kanser insidans çalışmalarında olduğu gibi, psoriasis ve malignite birlikteliği çalışmalarında da, sayılarının nispeten bildirilenden çok daha fazla olduğunun düşünülmesi ve bu nedenle doğru sayılarla doğru karşılaştırmaların yapılmasının zor olacağı, nedeni ile MM ve NM deri kanserleri hariç tutulmuştur [12]. Bizim çalışmamızda da, dermatoloji kliniklerinde kronik takipli psoriasis hastalarında, olası deri kanserlerinin normal populasyondan daha sı tanı alabileceği düşüncesi ile, yanlış veri yorumlanmasından kaçınmak için bu deri kanserleri analizlere alınmamıştır. Psoriasisde malignite risk artışı bildiren çalışmaların bir kısmında artan risk esas olarak lenfoproliferatif kanserler ve NM deri kanserleri için bildirilmiştir [13] ve bu, sonuçlardaki farklılığın sebeplerinden olabilir.

Psoriasiste malignite risk artışı bildiren çalışmalarda, esas olarak şiddetli psoriasislerde bu risk artışının anlamlı olduğu raporlanmıştır [13]. Bizim çalışmamızda 
psoriasis hastaları şiddetlerine göre gruplanmamıştır. Bu şekilde bir ayrımın farklı sonuçlar doğurup doğurmadığının araştırılması istenen çalışmada, kronik ve oldukça değişken seyirli bir hastalık olan psoriasisin dönemsel olarak aynı hastada farklı şiddetlerde olabilmesi, buna ek olarak şiddetli hastalarda etik nedenlerden ötürü sistemik tedaviler devam edeceğinden, izole psoriasis etkisinin değerlendirilmesinin yine de mümkün olamayabileciği düşünülmüştür. Literatürde şiddetli psoriasis vakalarında artmış malignite riski bildiren çalışmalarda da tedavilerinden bağımsız tüm hastaların dahil edildiği, dolayısı ile sistemik tedavilerin etkilerinin de dışlanamayacağı göz önüne alınmalıdır.

Çalışmamızda psoriasis hastalarında immünsupresif geleneksel tedaviler ve biyolojik ajan kulanımı ile de kanser artışı saptanmamıştır. Literatürde bu sonuçlarla uyumlu yayınlar mevcuttur [8]. Ancak bu sonuçları değerlendirirken, normal koşullarda kanser insidansının genellikle yılda 10.000 kişide birkaç vakadan çok daha az olduğu [14]; tedavilerin de malignite ile ilişkisini güvenilir bir şekilde belgelemek için daha geniş bir hasta örnekleminin daha farklı sonuçlar doğurabileceği akılda tutulmalıdır. Psoriasiste geleneksel ajanlardan olan metotreksat kullanımı ve malignite riski ile ilgili çalışmalar metotreksat maruziyeti ile artmış bir riski göstermemiş ancak, çoğunlukla nispeten küçük vaka serilerinden oluşmaktadır [9]. Psoriasis tedavisinde kullanılan bu immünsupresif tedavilerin maligniteyi arttırma etkilerinin bizim örneklem boyutumuzda göz önüne çıkacak kadar yüksek oranlarda olmadığı sonucuna varabiliriz. Bununla birlikte, mevcut verilerle ve literatür bilgisi ile, bu ilaçların malignite riskini hiçbir ölçüde arttırmadığı çıkarımı doğru olmayacaktır.

Pek çok kanser türünde, çeşitli ajanlara maruziyetten itibaren kanser ortaya çıkana kadar geçen latent periyod ortalama 0,4-11 yıl olarak bildirilse de, 57 y1l sonunda maruziyete bağlı kanser bildirileri mevcuttur [15]. Psoriasisin sistemik tedavisi ile ilişkili uzun vadeli malignite riskine ilişkin veriler nispeten azdır [9]. Biyolojik ajanlardan ustekinumab ile yapılan PHOENIX I ve II çalışmalarının uzun vadeli takibinde, malignite oranlarının Ulusal Kanser Enstitüsü gözlemleri ve epidemiyolojik beklenen oranlarla benzer olduğu öne sürülmüştür [16]. Ancak bu çalışmalarda da takip 5 yıl ile sınırlıdır. Bizim çalışmamız da beş yıllık verilerin retrospektif analizini içermekte olup, sonuçları sadece kısa dönemde ortaya çıkabilecek olan kanserler için yorumlanabilir. Konu ile ilgili ileri çalışmalarda daha uzun yıllar hasta takipleri farklı sonuçları ortaya koyabilir.

Sonuçların yorumlanmasında dikkate alınması gereken bir başka nokta tedavide kalım süresidir. Ustekinumab, infliksimab, adalimumab, etanersept gibi biyolojik ajanlar ve diğer geleneksel sistemik ajanlarla tedavi edilen veya tedaviye aday olan psoriasisli hastalar için güvenlik ve klinik sonuçları değerlendiren longitudinal gözlemsel bir çalışma olan PSOLAR çalışmasının sonucunda sadece 12 ay ve daha uzun süre biyolojik ajan kullanımı olan hastalarda malignite risk artışı bildirilmiştir [9]. Çalışmamızda kısa süreli tedavi alan hastaların da birlikte analiz edilmesi, uzun süre tedavi alan hastalarda kanser riskini istatistiksel olarak maskelemiş olabilir.

Retrospektif bir çalışma olduğu için kanser riskini arttırabilecek her parametrenin tam kontrolünün sağlanamaması bu çalışmanın kısıtlılığıdır. Bu konudaki belirsizliklerin giderilmesi için, oldukça büyük ölçekte, hasta dosyalarının birebir takip edildiği, uzun yıllar sürecek şekilde planlanmış, prospektif randomize kontrollü çalışmaların gerçekleştirilmesine ihtiyaç vardir.

\section{Sonuc}

Çalıșmamızın sonucunda, beş yıllık takipte psoriasise ya da tedavisinde kullanılan ilaçlara bağlı artmış bir malignite riski saptanmamıştır. Psoriasiste kanser riskinin arttığını söyleyebilmek için literatürde de yeterli ve kanıt düzeyi yüksek veriler mevcut değildir. Önceden yapılmış çalışmaların ve bu çalışmanın sonuçları; bazı çalışmalarda hesaplamalara deri kanserlerinin dahil edilmesiyle ortaya çıkan yanıltıcı veriler, kanserlerin seyrek insidansları, ortaya çıkma sürelerinin gecikebilmesi, tedavide kalım oranlarının değişebilmesi gibi faktörler dikkate alınarak yorumlanmalı ve psoriasisin ya da tedavilerinin malignite riskini hiçbir ölçüde arttırmayacağı çıkarımı da yapılmamalıdır. Daha büyük ölçekte ve daha uzun yıllar, hasta dosyalarının birebir takip edildiği çalışmalar, daha farklı insidanslar ortaya koyabilir.

\section{References}

1.Öztürk, F, Ermertcan, A.T, Gençoğlan, G, Temiz, P, İnanır, I, Isolated Face Involvement In Psoriasis, Celal Bayar Üniversitesi Sağlık Bilim Enstitüsü Dergisi, 2015, 2(4), 97-99.

2. Chen, Y.J, Wu, C.Y, Chen, T.J, et al., The risk of cancer in patients with psoriasis: A population-based cohort study in Taiwan, The Journal of the American Academy of Dermatology, 2011, 65(1), 84-91.

3. de Oliveira, M, de FSP, Rocha, B, de O, Duarte, G.V, Psoriasis: Classical and emerging comorbidities, Anais Brasileiros de Dermatologia, 2015, 90(1), 09-20.

4. Çiftçi, N, Tarihi, G, Üniversitesi, G, et al., Hücre İçi Kalsiyum Sinyali, Apoptoz ve Kanser Progresyonunda Kalsiyum Kanallarının (Voc, Trp ve Soc Kanalları) Rolü, Celal Bayar Üniversitesi Sağlık Bilimleri Enstitüsü Dergisi, 2017, 4(3), 1021-1027.

5.Balçık, Erçin, P, SIX1 ve Kanser Kök Hücre Belirteçlerinin Hepatoselluler Karsinomada Kapsamlı Analizi, Celal Bayar Üniversitesi Sağlık Bilim Enstitüsü Dergisi, 2020, 7(3), 325-330.

6. Kabadayı, H, Kıvanç, M, Seda, Vatansever H, SALL4-STAT3 Relations In Primary And Metastatic Colon, Breast And Endometrial Cancer Cell Lines, Celal Bayar Üniversitesi Sağlık Bilimleri Enstitüsü Dergisi, 2016, 3(4), 460-465.

7.Reddy, S.P, Martires, K, Wu, J.J, The risk of melanoma and hematologic cancers in patients with psoriasis, The Journal of the American Academy of Dermatology, 2017, 76(4), 639-647.

8. Kimball, A.B, Schenfeld, J, Accortt, N.A, Anthony, M.S, Rothman, K.J, Pariser, D, Cohort study of malignancies and hospitalized infectious events in treated and untreated patients with psoriasis and a general population in the United States, British Journal of Dermatology, 2015, 173(5), 1183-1190.

9. Fiorentino, D, Ho, V, Lebwohl, M.G, et al., Risk of malignancy with systemic psoriasis treatment in the Psoriasis Longitudinal Assessment Registry, The Journal of the American Academy of Dermatology, 2017, 77(5), 845-854.e5.

10. Fuxench, Z.C.C, Shin, D.B, Beatty, A.O, Gelfand, J.M, The risk of cancer in patients with psoriasis a population-based cohort study in the health improvement network, JAMA Dermatology, 2016, 152(3), 282290. 
11. Pouplard, C, Brenaut, E, Horreau, C, et al., Risk of cancer in psoriasis, A systematic review and meta-analysis of epidemiological studies, The Journal of the European Academy of Dermatology and Venereology, 2013, 27(SUPPL.3), 36-46.

12. Geller, S, Xu, H, Lebwohl, M, Nardone, B, Lacouture, M.E, Kheterpal M, Malignancy Risk and Recurrence with Psoriasis and its Treatments: A Concise Update, The American Journal of Clinical Dermatology, 2018, 19(3), 363-375.

13. Margolis, D, Bilker, W, Hennessy, S, Vittorio, C, Santanna, J, The risk of malignancy associated with psoriasis, Archives of Dermatology 2001, 137(6), 778-783.

14. Naldi, L, Malignancy concerns with psoriasis treatments using phototherapy, methotrexate, cyclosporin, and biologics: facts and controversies, Clinics in Dermatology, 2010, 28(1), 88-92.

15. Minimum Latency \& Types or Categories of Cancer, https://www.cdc.gov/wtc/pdfs/policies/wtchpminlatcancer2014-11-07508.pdf, 2014 (accessed 29.22.2020)

16. Langley, R.G, Lebwohl, M, Krueger, G.G, et al., Long-term efficacy and safety of ustekinumab, with and without dosing adjustment, in patients with moderate-to-severe psoriasis: Results from the PHOENIX 2 study through 5 years of follow-up, British Journal of Dermatology, 2015, 172(5), 1371-1383.

http://edergi.cbu.edu.tr/ojs/index.php/cbusbed isimli yazarın CBU-SBED başlıklı eseri bu Creative Commons Alıntı-Gayriticari4.0 Uluslararası Lisansı ile lisanslanmıştır.

cc) (i) \& 